\title{
BMJ Open Listening to paediatric primary care nurses: a qualitative study of the potential for interprofessional oral health practice in six federally qualified health centres in Massachusetts and Maryland
}

\author{
Judith Bernstein, ${ }^{1,2}$ Christina Gebel, ${ }^{1,2}$ Clemencia Vargas, ${ }^{1,3}$ Paul Geltman, ${ }^{1}$ \\ Ashley Walter, ${ }^{1,2}$ Raul Garcia, ${ }^{1}$ Norman Tinanoff ${ }^{1,3}$
}

To cite: Bernstein J, Gebel C, Vargas $\mathrm{C}$, et al. Listening to paediatric primary care nurses: a qualitative study of the potential for interprofessional oral health practice in six federally qualified health centres in Massachusetts and Maryland. BMJ Open 2017;7:e014124. doi:10.1136/bmjopen-2016014124

- Prepublication history and additional material is available. To view please visit the journal (http://dx.doi.org/ 10.1136/bmjopen-2016014124).

Received 2 September 2016 Revised 17 January 2017 Accepted 14 February 2017

CrossMark

For numbered affiliations see end of article.

Correspondence to Dr Judith Bernstein; jbernste@bu.edu

\section{ABSTRACT}

Objectives: To explore the opportunities for interprofessional collaboration (IPC) to improve paediatric oral health in federally qualified health centres (FQHCs), to identify challenges to IPC-led integration of oral health prevention into the well-child visit and to suggest strategies to overcome barriers.

Sample: Nurse managers (NMs), nurse practitioners (NPs), paediatric clinical staff and administrators in six FQHCs in two states were interviewed using a semistructured format.

Design: Grounded theory research. Topics included feasibility of integration, perceived barriers and strategies for incorporating oral health into paediatric primary care. Measurements: Qualitative data were coded and analysed using NVivo 10 to generate themes iteratively.

Results: Nurses in diverse roles recognised the importance of oral health prevention but were unaware of professional guidelines for incorporating oral health into paediatric encounters. They valued collaborative care, specifically internal communication, joint initiatives and training and partnering with dental schools or community dental practices. Barriers to IPC included inadequate training, few opportunities for cross-communication and absence of charting templates in electronic health records.

Conclusions: NMs, NPs and paediatric nursing staff all value IPC to improve patients' oral health, yet are constrained by lack of oral health training and supportive charting and referral systems. With supports, they are willing to take on responsibility for introducing oral health preventive measures into the well-child visit, but will require IPC approaches to training and systems changes. IPC teams in the health centre setting can work together, if policy and administrative supports are in place, to provide oral health assessments, education, fluoride varnish application and dental referrals, decrease the prevalence of early childhood caries and increase access to a dental home for low-income children.

\section{Strengths and limitations of this study}

- In-depth, open-ended interviews with nurses working in different roles and levels of authority in federally qualified health centres in two states allowed frank discussion of benefits and challenges to inclusion of oral health prevention topics in well-child visits.

- Engagement of clinic administration and staff was facilitated by procedures for protection of confidentiality, which allowed sensitive material about attitudes and knowledge to emerge.

- Collaborating clinics were selected to represent urban, rural and suburban clinics in states with different systems of financing and allocation of health resources, allowing for saturation of themes.

- Qualitative approaches are effective for identification of key issues for consideration in developing strategic interventions, but are not designed for generalisability beyond the specific settings that were studied.

\section{BACKGROUND}

Early childhood caries (ECC) remains a pervasive, burdensome problem and the most common chronic childhood illness. ${ }^{1}{ }_{2}$ Evidence-based approaches to reduce ECC include identifying high-risk children at an early age, coordinating care and referrals to a dental home by age one, and integrating oral health into paediatric primary care through anticipatory guidance and behaviour modification counselling. ${ }^{3-5}$ It is suggested that paediatric oral health is the next frontier for prevention. ${ }^{6}$ The aim of this qualitative study was threefold: (1) to investigate what nurses working with high-risk paediatric patients in a structured clinical 
setting believe and know about their potential to engage fully in collaborative practice to promote children's oral health; (2) to identify the barriers and challenges to role expansion that nurses experience in low-resource primary paediatric care settings and (3) to elicit their recommendations for enhancing their role in paediatric oral health prevention.

Robust approaches to prevention require interdisciplinary and interprofessional collaboration (IPC)..$^{7} 8$ A recent multiorganisational report calls for the "partnering of primary care and dental health professionals to reduce the burden of oral disease', ${ }^{6}$ and existing literature supports the importance of integrating dental and medical care in the primary care system. $\begin{array}{llll} & 7 & 9 & 10\end{array}$ Worldwide, WHO policy, established collectively with the FDI Science Commission and the International Association for Dental Research, calls for an interprofessional effort to scale up capacity to produce oral health personnel, including dental hygienists, nurses and auxiliaries, providing for equitable distribution of these auxiliaries to the primary care level and ensuring proper service backup by dentists through appropriate referral systems. ${ }^{11}$

Nurses are uniquely positioned to foster IPC. Cooperation between nurse practitioners (NPs) and dieticians, for example, can be used to expand the dental workforce. IPC teams work together to provide oral health assessments, education, fluoride varnish application and dental referrals, decrease the prevalence of ECC and increase access to a dental home for lowincome children. ${ }^{10}$ Referrals are important because children aged 2-5 years who receive a recommendation for a dental home are more likely to have a dental visit. ${ }^{12} 13$

Fewer than half of children on Medicaid receive a preventative dental visit each year, ${ }^{14}$ and one in seven patients (paediatric and adult) at federally qualified health centres (FQHCs) reported their most recent dental visit was $>5$ years ago. ${ }^{15}$ In a study of paediatric primary care physicians, $21 \%$ reported not screening for oral health due to lack of resources for referring patients to dental care and $42 \%$ reported difficulty integrating dental procedures into their practices. ${ }^{16}$ In another study, $96 \%$ reported that the most common method for dental referral was to provide the name of a dentist without assistance in making the appointment. ${ }^{17}$

IPC models, which are mandated by federal legislation $^{18}$ and supported by dental and medical professionals ${ }^{19}$ have the potential to increase oral health screening, referral and service capacity. ${ }^{20}$ They also aid in meeting accreditation standards and encourage implementation of practice guidelines, ${ }^{21}$ increase quality and efficiency ${ }^{22}$ and improve access for uninsured and underserved populations. ${ }^{23}$

We conducted a multimethod case study in six FQHCs with a medical home designation to investigate challenges to implementation of dental, medical and nursing collaboration, with the primary goal to understand how all roles within a clinic setting, including nurses, NPs, medical assistants, physicians, dental clinicians (where applicable), nurse managers (NM) and other administrators can work together to improve oral health. ${ }^{24}$ This current report describes findings from the subset of interviews with nurses across settings and nursing roles, describes their perspectives and challenges and the supports they would need to enhance the feasibility of IPC.

\section{METHODS}

This study was reviewed and classified under exempt status by the Institutional Review Boards at Boston University and University of Maryland, where coinvestigators were located, and at University of Baltimore, where interviewers were located. Participants completed an informed consent to be interviewed by telephone and to have the conversation recorded and transcribed.

The research team of seven, four women and three men, included five senior researchers.

\section{Design}

We selected three FQHCs in state 1 and three in state 2 to represent a continuum of oral health integration into paediatric services and a range of geographic locations (rural, small community and urban), organisational structures, patient populations, workforce composition and financial resources across a continuum of oral health integration into paediatric services. Contextual, organisational and professional data were collected from August 2014 through March 2015.

We then conducted key informant interviews over a 6-month period to analyse contextual, organisational and professional factors that may facilitate or hinder IPC in paediatric oral health.

\section{Research team and reflexivity}

Each clinic administrator identified potential interviewees who were knowledgeable about conditions in their paediatric well-child clinics, explained the purpose of the study and asked if they were willing to be interviewed by telephone. Two independent interviewers from the faculty of the University of Baltimore (WW, DM) were provided with a list of interested interviewees from each clinic. They used this list to send introductory emails describing their qualifications, and then called to introduce themselves, review the study purpose, ascertain willingness to participate and conduct an informed consent process. The research team included dental and medical clinical faculty with advanced degrees $(\mathrm{PhD}$, MS, MMSc and MPH) in related fields.

\section{Theoretical framework}

Methodologic orientation: domains of inquiry were established based on the four content areas of the Consolidated Framework for Implementation Research: the nature of the intervention (in this case, introduction of oral health prevention into the well-child visit), 
characteristics of children and their families, characteristics, attitudes and experiences of nurse clinicians and NMs (the inner context) and policy concerns (the outer context). The theoretic framework thus used content analysis and grounded theory. Study quality was addressed through use of the Consolidated Criteria for Reporting Qualitative Research (CORE-Q).

\section{Sample}

Clinic decision makers, nursing, medical and dental clinicians and support personnel were identified for interview by each clinic director. Selection of potential participants as role experts was purposive, designed to capture the expertise of paediatric primary care nurses across job descriptions (NM/charge nurse, registered nurse (RN) and NP) and within each clinic named in each state. In all, 42 contacts were named and 39 interviewed. All 10 of the nurses who were named by the administrators in the six clinics agreed to participate and completed interviews, and therefore constitute the sample for this investigation. Among them, there were five NMs, three NPs and two RNs, with all clinics represented. This sample was large enough to allow a broad generation of themes but small enough to limit burden and increase the likelihood that the clinics would agree to participation.

\section{Setting}

Confidential 1-hour interviews were conducted with one of the two University of Baltimore interviewers over the telephone number of participants' choice, at their convenience.

\section{Measures}

Interviewers used a semistructured interview schedule with cues and prompts to elicit relevance of oral health for general health, current oral health practices, degree of integration and feasibility of oral health activities as part of paediatric primary care, acceptable methods for integration, perceived facilitators and barriers for integration and potential strategies to address barriers. Questions were generated building on previously piloted items. ${ }^{6}$ The interview schedule is available as an online supplementary file.

\section{Protection of confidentiality}

The goal of this study was to promote full disclosure. Clinic administrators agreed to participation based on expectation of protection of confidentiality. For this reason, the sites that participated are not identified, and the individuals who were interviewed are identified in quotes only by their roles in clinic operation.

\section{Analytic strategy}

The data analytic process was designed to explore how factors related to the professional training and expertise of nurses and the hierarchical clinic culture they work in might affect nurses' ability and willingness to engage in IPC. Audio recordings were transcribed. Two experienced qualitative data analysts and a senior faculty member of the research team at Boston University independently coded three key informant interviews and assigned initial codes using inductive coding methods. The three team members then met to discuss the proposed code list and resolve any differences in interpretation. A list of agreed-on first-level codes were entered into a master code list using NVivo 10 software with accompanying code definitions so coding was consistent across interviews. Codes were assigned to three interview transcripts by two qualitative data analysts. Inter-rater reliability was assessed and the three interviews recoded independently until inter-rater reliability was satisfactory ( $\kappa$ coefficient $>0.70$ ). The remainder of the interviews were coded, and new codes were discussed, defined and added to the master list until the list reached saturation. Once all data were coded, the three team members met to assess theme characterisation from final codes, referring to interview field notes as well as transcripts. Interviewees were not contacted for clarifications and did not receive feedback.

\section{RESULTS}

Ten of the 39 interviews from the parent study were with nursing participants in three roles: NM, NPS and RN. Three overarching themes emerged from these interviews: (1) recognition by nurses of the importance of oral health to paediatric general health and development, as a sine qua non for engagement in IPC; (2) facilitators and barriers to IPC and (3) nursing recommendations for enhancing IPC. Nursing responses largely reflected the sentiments of other paediatric and administrative staff, but nurses, overall, were much more willing to see integration of oral health content as a nursing responsibility, but only if appropriate training was made available. The nursing interviews generated concrete, useful suggestions for addressing barriers. We present here major and minor themes, which emerged with clarity and consistency.

\section{Recognition by nurses of patients' needs and a role for IPC in paediatric oral health}

Nurses across different roles and levels of authority made a clear connection between oral health and children's physical, mental and social development:

I think it's very important because...the mouth is opening to the rest of the body...We have kids that I know of that have a hard time sitting in school because their mouths hurt so much. [NM]

Interviewees were concerned about the consequences of lack of prevention:

There are a lot of kids who have so many caries that need to be fixed or extractions that need to be done that they end up having to be fully sedated for the procedures. [NP] 
Some of the interviewees thought that parental neglect was responsible for the poor oral hygiene and high rates of ECCs that are common in their patients:

Neglect is on top of the list....Parents/teachers don't have a clue, you know, baby bottle tooth decay, just awful, rampant. They don't admit that they put the baby to bed with the bottle but you know that they do because you just see the powder in the mouth clearly. [NP]

Nurses described a low level of oral health literacy among parents who use services at a FQHC:

A lot of them just, unfortunately...don't realize that they need preventative dental services just like they need well child visits. $[\mathrm{NP}]$

The lack of oral health awareness was particularly noted among the diverse immigrant families who use FQHCs:

I think the patients that we get who are immigrants don't understand [that] having multiple bad teeth affects their eating, their sleeping, how they do in school. [NP]

Interviewees reflected on when their own children were young and the problems they had themselves with brushing and getting dental care:

Baby teeth... "They are going to fall out anyway." And I think for some parents, that may be the point of reference that they are coming from...Dentists try to preserve baby teeth and keep the alignment [for] their second teeth. And I'm not sure that that's a message that the parents...have gotten. [NM]

There was also understanding of the competing family priorities for FQHC patients:

Life is expensive and there's bills for everything and dental services seems like a luxury for some that can't afford it, and so that's the one thing that gets forgotten. [NP]

And:

A large majority of our parents want their kids to be well and to not have issues. I'm just not sure that they have the resources to know where they need to go, to go to the dentist for their kids. [NM]

Oral health content was seen to be consistent with the concept of a medical home that is an organising principle for FQHCs:

Bringing in oral health, dental. It definitely supports the model of the patient center medical home. Where we live we have terrible winters...And if you only have to make one stop, I think that would be something that people would like. [NM]
There was broad acceptance of responsibility for prevention:

When we see kids especially in the course of well child visits, we discuss last dental appointment, oral hygiene, brushing the teeth because, unfortunately, some kids and parents are unaware that that's necessary. Talking about sugary drinks and foods is not only a part of the physical examination but it's also a part of anticipatory guidance. [NP]

And that responsibility extends to charting:

I always document if they brush their teeth [and] that they've been to the dentist in the last six months, [and] diet in terms of limiting juice, no soda, limit candy and high-sweetened snacks. [NP]

Several interviewees were in favour of a collaborative approach to healthcare delivery:

I mean, you can't separate the mouth from the child and the dentist from the medical provider. It all needs to be integrated. [NP]

And:

I really think in terms of education that this would be opportunity for the nurses to step forward and do some more stuff, the stuff the pediatricians don't need to directly do. And I'd like to see that happen. [NM]

\section{Facilitators to integration of oral health into paediatric well-childcare}

Interviewees mentioned many benefits of incorporating oral health preventive services into paediatric practice:

If we can see them young and talk about it, hopefully we're having them make behavioral change so they don't suffer the same problems as other adults in their families do. $[\mathrm{NP}]$

The paediatric well-child visit was seen as an optimal setting for prevention:

It just seems to me that kids have a better relationship with their primary care provider than they do their dentist. The dentist's office is often a scary place to be for children. [NM]

And:

We do fluoride treatments for our kids already. And I think that a lot of parents respect our pediatricians, and then if it came from the pediatrician, it would hold more weight. [NM]

Many nurses also thought about efficiencies that might result:

I think it's beneficial if you do as much as you can when they're here in front of you. Our families often have 
difficulty making it to multiple appointments. So there's probably something we could incorporate during a visit to ...emphasize the point that we also consider oral health when we're considering the children's overall health. [Pediatric Nurse Practitioner]

Others, especially at the RN level, were sceptical about ability to deliver, and concerned about delegating any tasks to extenders:

I don't see any of our staff having time or a person just devoted directly to dental... [and] I don't think that assistants should be scheduling appointments at all, but I do feel that they can certainly send us messages where we can contact the patient and follow-up. But I don't feel that they are necessarily medically trained. [RN]

\section{Barriers to IPC}

There was a general lack of awareness of professional guidelines for preventive education and services in paediatrics or paediatric dentistry:

I'm assuming that they have them. I don't know what they are currently. [NP]

Space is always an issue in FQHCs:

Space will probably be the biggie. But again, if we were going to incorporate it in each appointment and we didn't need special stuff like a dental chair, we'd be okay about that. [NM]

Time is limited:

They only get primarily $15 \mathrm{~min}$ with each patient, so I know that it's very hard for them to fit [in] every single thing that they have to do with a patient...A lot of our patients have health disparities, mental health issues, and dental probably isn't top of the list, but I believe with more time they would definitely incorporate that. $[\mathrm{RN}]$

Electronic medical record systems posed a significant barrier to integration in each of the clinics that were studied:

If the dentist was concerned about nutritional status...we don't often get that information. While we are all connected under the health center, we are sort of together but we are separate. $[\mathrm{RN}]$

Respondents expressed a strong desire to have crosscommunication and saw this as a logical next step, since both systems report on a patient's health. However, nurses reported not knowing about the activities of their colleagues:

Well, I haven't seen what happens on the dental side because they are not here at my site. [NP]

Charting for paediatric and dental clinicians was in entirely different systems:
If you as the provider... actually had medical records that could talk to each other, like EPIC does, then [the dentist] could see what was going on medically... and you could see what they're doing; that would be absolutely wonderful. [NM]

The lack of templates for oral health was also mentioned:

I have to 'free text' that they've been to the dentist, that they brush their teeth, ...that all has to be added on by me. If there was a template where we could just click on that, it would be great. [NP]

Respondents spoke of their lack of oral health knowledge and the need for training in this area:

I really feel like I probably need some additional training; Nurse-Practitioners are deficient in dental training. [NP]

And:

I would really like to get some additional hands-on training for the dental examination. I mean, I can go in there and look around in the mouth...but I may miss what I'm looking for. [NP]

Nurses and NPs were open to collaboration with extenders, as long as they received the proper training:

I think training just has to match what you're asking people to do. So if you're asking them to do a new procedure, they need the training to do that. [NP]

And:

Then the medical assistant could do the fluoride application at the end of the visit, as well as give them a toothbrush, and possibly some kind of book for the child, or coloring page, or something. [NM]

Nurses were concerned about the lack of systems in place for tracking referral outcomes:

That is a terrible deficiency that I hope they make the appointment and then they go to the clinic and that's where I lose it, unfortunately, in the loop. [NP]

Additional resources are needed:

Visuals mean everything. Kids see pictures....You can hand out type-written stuff forever, but when a child looks up and sees pictures of bad teeth, they respond to it. And parents look at it and they, you know, just a simple picture with caption: This is baby bottle tooth decay. This is what happens when you don't brush. [NP]

Colocation of paediatric and dental services would help: 
I definitely think co-location would help. It's very hard for our parents.... The parents know this site already and they know how they're going to get there. [NM]

But what was needed even more was administrative leadership and champions:

I do think it would be helpful to designate a team leader, a person that's kind of the advocate, who helps with training or setting up training. [NP]

\section{DISCUSSION}

The success of IPC depends on confluence of three domains: interpersonal processes, communication channels inside the organisation, in this case, a clinic and in the organisation's external environment. ${ }^{24} 25$ Respondents in this study reported efforts towards dental, medical and nursing collaboration, as well as structural, cultural and educational barriers that complicate, stall or prevent the positive influence of these efforts.

\section{Structural barriers}

Efforts towards interdisciplinary team-based collaboration can be complicated by professional boundaries, sometimes referred to as 'professional silos' or 'the silo effect', ${ }^{26} 27$ as well as challenges from professional cultures, defined as a profession's 'values, beliefs, attitudes, customs and behaviours' ${ }^{28}$ Differences in power to make decisions were noticeable; RNs were more likely to feel sceptical about instituting change, while NPs and NMs appeared to be more receptive to integration of oral health into the wellchild visit, perhaps because they felt more able to communicate their needs upward in the administrative chain.

\section{Cultural barriers}

The surgeon general has called for a shift in the perception that oral health is solely the responsibility of dentists, encouraging all clinicians-dental, medical and nursing-to participate in improving oral health to improve overall health status and adoption of collaborative, interdisciplinary approaches to care. ${ }^{7}$ Nurses felt the need for systematic training to take on these new responsibilities.

\section{Educational barriers}

The reported lack of confidence in expertise is certainly due to the scarcity of training in oral health noted here and described by the DentaQuest Foundation. ${ }^{29}$ The surgeon general has called for changes to clinical curricula to include oral health and multidisciplinary training in continuing medical education offerings. ${ }^{30}$ For example, providers need further education in assessment and use of assessment tools in order to improve accuracy in visible exams in well-childcare. ${ }^{31}$ In one study by AlYousef et $a l,{ }^{32} 87.5 \%$ of medical students rated their training in oral health assessments as fair or poor, though $90 \%$ believed the role of providers counselling children in oral health and referring them to treatment was important. The knowledge deficit that we identified could be remedied by teaching students' oral examination as part of standard head, ears, eyes, nose and throat (HEENT) examinations. ${ }^{33}$ The NPs in this study who were unaware of guidelines, did not use an assessment tool and seemed uncertain as to what such a tool might contain, would certainly benefit from additional training in order to make such efforts standard practice.

IPC in education has been shown to improve NPs' core competencies in oral health ${ }^{34}$ and could be part of a solution to overcoming the barriers described in this study. Innovative models are already in use, as well as guidance for how to integrate IPC models into curricula. ${ }^{35}$ In the field of nursing, options for IPE education could include service learning projects as well as inclusion of intervention strategies for oral health in standard curricula. $^{36}$ Toolkits and resources are available for nurse educators for competencies development. ${ }^{37}$ Projects and dissemination could be core components of overall educational infrastructures, which include competencies to 'prioritise oral health disease prevention and health promotion, provided evidence-based oral healthcare in a variety of practice settings, and collaborate in interprofessional teams across the healthcare system'. ${ }^{38}$ The Oral Health Nursing Education and Practice (OHNEP) programme at New York University's College of Nursing calls for a national nursing action plan with short-range, mid-range and long-range nursing strategies to advance the nation's oral health agenda; a National Nursing Workgroup on Oral Health; and train-the-trainer workshops for faculty and students, among other efforts. ${ }^{37} 38$

\section{Advantages and limitations of this study}

This study details through the lens of nursing practice the need for IPC in paediatric oral health, and identifies specific areas that require attention to enable nurses in the FQHC setting to collaborate across professional boundaries. As such, it adds to a growing body of literature on the need for IPC to improve patients' oral health status. Qualitative research adds depth and suggests important themes, but is necessarily limited in breadth by small samples derived from six clinics in three states. The 2015 White Paper on oral health into paediatric primary care $^{6}$ sets a clear path for us in stating that 'Oral health is the next frontier'. The IPC approaches needed to explore that frontier require changes in training and systems, and much work needs to be done to establish feasible, affordable strategies to reach the preventive goals set by major organisations in the USA and worldwide; this study, while limited by scope, suggests some useful directions.

Although the study was broad in the sense that it included clinics of different geographical settings and size in two states, generalisability of results is limited by the small sample interviewed from each clinic, and the small number of clinics that served as the setting for this study. 


\section{CONCLUSIONS}

NMs, NPs and paediatric nursing staff interviewed in this study all valued IPC to improve patients' oral health, yet reported feeling constrained by lack of oral health training and supportive charting and referral systems. With supports, they would take on responsibility for introducing oral health preventive measures into the well-child visit, but will require IPC approaches to training and systems changes if they are to take an active role in oral health prevention. IPC teams in the health centre setting can work together, if policy and administrative supports are in place, to provide oral health assessments, education, fluoride varnish application and dental referrals, decrease the prevalence of ECCs and increase access to a dental home for low-income children. Caution should be exercised in generalising from this study, but in the clinics that were included, nurses clearly had the potential and willingness to work towards improvements in children's oral health if supports were provided.

\section{Author affiliations \\ ${ }^{1}$ Center for Research to Evaluate and Eliminate Dental Disparities, Boston University Henry M. Goldman School of Dental Medicine, Boston, Massachusetts, USA \\ ${ }^{2}$ Department of Community Health Sciences, Boston University School of Public Health, Boston University, Boston, Massachusetts, USA \\ ${ }^{3}$ Department of Orthodontics and Pediatric Dentistry, University of Maryland School of Dentistry, Baltimore, Maryland, USA}

Contributors JB, CG, CV, PG, AW, RG and NT all participated in study design and implementation, interpretation of study findings and writing of this report.

Funding This study was supported in part by a cooperative agreement with the National Institute of Dental and Craniofacial Research, National Institutes of Health (U54-DE019275).

Competing interests None declared.

Ethics approval Boston University's Institutional Review Board was the lead university on this project.

Provenance and peer review Not commissioned; externally peer reviewed.

Data sharing statement Small cells and a need to protect confidentiality of participating nurses and their clinics preclude release of identifiable tapes or transcripts, and Nvivo codes include identification of clinic and participant. The authors are happy to respond to queries from researchers interested in this topic.

Open Access This is an Open Access article distributed in accordance with the Creative Commons Attribution Non Commercial (CC BY-NC 4.0) license, which permits others to distribute, remix, adapt, build upon this work noncommercially, and license their derivative works on different terms, provided the original work is properly cited and the use is non-commercial. See: http:// creativecommons.org/licenses/by-nc/4.0/

\section{REFERENCES}

1. Institute of Medicine. Advancing oral health in America. 2011. http:// books.nap.edu/openbook.php?record_id=13086 (accessed 30 Aug 2016).

2. Department of Health and Human Services, \& U.S. Public Health Service. Oral health in America: a report of the surgeon general. National Institute of Dental and Craniofacial Research, National Institutes of Health. 2000. http://www.nidcr.nih.gov/DataStatistics/ SurgeonGeneral/Documents/hck1ocv.@www.surgeon.fullrpt.pdf (accessed 30 Aug 2016)

3. Kagihara LE, Niederhauser VP, Stark M. Assessment, management, and prevention of early childhood caries. J Am Acad Nurse Pract 2009;21:1-10.
4. Crall JJ. Development and integration of oral health services for preschool-age children. Pediatr Dent 2005;27:323-30.

5. Hale KJ, and the American Academy of Pediatrics Section on Pediatric Dentistry. Oral health risk assessment timing and establishment of the dental home. Pediatrics 2003;111(Pt 1):1113-16.

6. Hummel J, Philips K, Holt B, et al. Oral health: an essential component of primary care (White Paper.). Seattle, WA: Qualis Health. 2015. http://www.nasuad.org/sites/nasuad/files/ White-Paper-Oral-Health-Primary-Care.pdf (accessed 30 Aug 2016).

7. US Department of Health and Human Services. Oral health in America: a report of the surgeon general. J Calif Dent Assoc 2000;28:685-95.

8. Wagner $Y$, Heinrich-Weltzien R. Evaluation of a regional German interdisciplinary oral health programme for children from birth to 5 years of age. Clin Oral Invest 2017;21:225-35.

9. Health Resources and Services Administration. Integration of oral health and primary care practices. Rockville, MD: US Department of Health and Human Services, 2014. http://www.hrsa.gov/publichealth/ clinical/oralhealth/primarycare/integrationoforalhealth.pdf (accessed 30 Aug 2016).

10. Biordi DL, Heitzer M, Mundy E, et al. Improving access and provision of preventive oral health care for very young, poor, and low-income children through a new interdisciplinary partnership. Am $J$ Pub Health 2015;105(Suppl 2):e23-9.

11. Petersen PE. World Health Organization global policy for improvement of oral health-World Health Assembly 2007. Internat Dent J 2008;58:115-21.

12. Beil HA, Rozier RG. Primary health care providers' advice for a dental checkup and dental use in children. Pediatrics 2010;126: e435-441.

13. Zilversmit L, Kane DJ, Rochat R, et al. Factors associated with receiving treatment for dental decay among Medicaid-enrolled children younger than 12 years of age in lowa, 2010. J Pub Health Dent 2015;75:17-23.

14. Mann C. Update on CMS oral health initiative and other oral health related items (CMCS Informational Bulletin). Baltimore, Maryland: Center for Medicaid and CHIP Services, 2014. http://www.medicaid. gov/Federal-Policy-Guidance/downloads/CIB-07-10-2014.pdf (accessed 30 Aug 2016).

15. Jones E, Shi L, Hayashi AS, et al. Access to oral health care: the role of federally qualified health centers in addressing disparities and expanding access. Am J Pub Health 2013;103:488-93.

16. Close K, Rozier RG, Zeldin LP, et al. Barriers to the adoption and implementation of preventive dental services in primary medical care. Pediatrics 2010;125:509-17.

17. dela Cruz GG, Rozier RG, Slade G. Dental screening and referral of young children by pediatric primary care providers. Pediatrics 2004;114:e642-52.

18. Edelstein BL. The roles of federal legislation and evolving health care systems in promoting medical-dental collaboration. J Calif Dent Assoc 2014;42:19-23.

19. Cohen LA. Expanding the physician's role in addressing the ora health of adults. Am J Pub Health 2013;103:408-12.

20. Taylor E, Marino D, Thacker S, et al. Expanding oral health preventative services for young children: a successful interprofessional model. J Allied Health 2014;43:e5-9.

21. Jackson JT, Quinonez RB, Kerns AK, et al. Implementing a prenatal oral health program through interprofessional collaboration. J Dent Educ 2015;79:241-8.

22. Formicola AJ, Ro M, Marshall S, et al. Strengthening the oral health safety net: delivery models that improve access to oral health care for uninsured and underserved populations. Am J Pub Health 2008;98(9 Suppl):S86-8.

23. Beetstra S, Derksen D, Ro M, et al. A "health commons" approach to oral health for low-income populations in a rural state. Am J Pub Health 2008;98(9 Suppl):S89-90.

24. Bernstein HH, Dhepyasuwan N, Connors K, et al., CORNET Investigators. Evaluation of a national bright futures oral health curriculum for pediatric residents. Acad Pediatr 2013;13:133-9.

25. San Martín-Rodríguez L, Beaulieu MD, D'Amour D, et al. The determinants of successful collaboration: a review of theoretical and empirical studies. J Interprof Care 2005;19(Suppl 1):132-47.

26. Vanderbilt AA, Dail MD, Jaberi P. Reducing health disparities in underserved communities via interprofessional collaboration across health care professions. J Multidiscip Healthc 2015;8:205-8.

27. Weller J, Boyd M, Cumin D. Teams, tribes and patient safety: overcoming barriers to effective teamwork in healthcare. Postgrad Med J 2014;90:149-54.

28. Hall P. Interprofessional teamwork: professional cultures as barriers. J Interprof Care 2005;19(Suppl 1):188-96. 
29. Mitchell-Royston L, Nowak A, Silverman J. Integration of oral health into pediatric medical primary care in community health centers. AAPD, The Pediatric Oral Health Research and Policy Center, Dentaquest Foundation, 2014:1-19. http://www.aapd.org/assets/1/7/ Dentaquest_Year_1_Final_Report.pdf (accessed 30 Aug 2016).

30. Peterson-Sweeney $\bar{K}$, Stevens J. Optimizing the health of infants and children: their oral health counts! J Pediatr Nurs 2010;25:244-9.

31. Dumas SA, Weaver KE, Park SY, et al. Accuracy of visible plaque identification by pediatric clinicians during well-child care. Clin Pediatr 2013;52:645-51.

32. AlYousef $\mathrm{Y}$, Damiano P, Weber-Gasparoni K, et al. Medical students' child oral-health-related knowledge, practices and attitudes. Eur J Dent Educ 2013;17:218-24.

33. Haber J, Hartnett E, Allen $\mathrm{K}$, et al. Putting the mouth back in the head: HEENT to HEENOT. Am J Pub Health 2015;105:437-41.
34. Hallas D, Fernandez JB, Herman NG, et al. Identification of pediatric oral health core competencies through interprofessional education and practice. Nurs Res Practice 2015;2015: 360523.

35. Haber J, Spielman Al, Wolff M, et al. Interprofessional education between dentistry and nursing: the NYU experience. J Calif Dent Assoc 2014;42:44-51.

36. Smith GA, Riedford K. Epidemiology of early childhood caries: clinical application. J Pediatr Nurs 2013;28:369-73.

37. Dolce MC, Aghazadeh-Sanai N, Mohammed S, et al. Integrating ora health into the interdisciplinary health sciences curriculum. Dent Clin North Am 2014;58:829-43.

38. Dolce MC, Haber J, Shelley D. Oral health nursing education and practice program. Nurs Res Pract 2012;2012: 149673. 